\title{
Treatment of repeated self- injurious behaviour with naltrexone: a case report
}

\author{
Praveen Navkhare, Abhishek Mamarde, Anand Lade
}

\section{Summary}

A wide array of behavioral techniques and psychotropic medications are used to treat self-injurious behaviour associated with mental retardation, autism and other developmental disabilities. The behaviors range from biting to mutilating self. We describe a young male patient with severe self-injurious behavior who was successful treated with naltrexone. Previous treatment with antipsychotics had not been effective.

SL J Psychiatry 2013; 4 (2):49-51

\section{Introduction}

The term self-injurious behavior is defined as deliberate injury to one's own body done without the aid of another person and is severe enough to cause tissue damage or scarring (1). The term self-injurious behavior has also been used in acts of deliberate self harm, self harm, self mutilation, parasuicide, self wounding, auto aggression and purposive accidents. However those acts, which are done with the intension to commit suicide, should be considered as a separate category as they are aware of the act and its consequences (2).

In DSM-5, the term self-injurious behavior is not categorized separately but is included in the category of stereotypic movement disorder which is a movement disorder under neurodevelopmental disorders (3). This includes stereotypic movements which result in injury. Self-injurious behavior is not considered a separate diagnostic entity but as symptoms which occur in conditions such as mental retardation, attention deficit hyperactivity disorder (ADHD) and oppositional defiant disorder (ODD). Severe forms of self-injurious behavior have been documented in psychotic and delusional disorder. The impulse control disorders, repetitive self mutilation and compulsive skin picking are associated with impulses to harm oneself and these impulses are intrusive, recurrent and irresistible and associated with increasing tension. Various instruments such as scissors, razor blades, knives, scalpels, glass, and pieces of metal can be used in self-injurious behaviour.

Reduced level of serotonin is associated with aggression, impulsivity, and self-injurious behaviors. Lower levels of metabolites of serotonin in spinal fluid or fewer platelet binding sites indicate low serotonin in the brain. Reduced serotonergic activity has also been demonstrated in borderline personality disorder, major depressive disorder, obsessive compulsive disorder and mental retardation, which can result in impulsiveness, aggression, and self-injurious behavior (4). In addition dopamine is also implicated in self-mutilation. Selfinjurious behaviors are seen in individuals with Lesch-Nyhan syndrome and sometimes Tourette syndrome, which are both disorders that involve dysregulation of dopaminergic activity and dopamine receptor super sensitivity (5-6).

The role of endorphins in maintaining self-injurious behavior has also been researched. Two theories have been postulated. In the addiction hypothesis, self-injury leads to release of endogenous endorphins. This abnormal behavior is reinforced through operant conditioning. The triggering behavior may include excessive self-stimulatory behavior, initiated as a means to either avoid or obtain attention, as a form of communication, or to compensate for a dopamine regulatory defect. Over time, however, the release of endogenous endorphins not only masks the discomfort but also may generalize to mask other forms of discomfort or even be a source of comfort or euphoria.

A second theory for the role of endogenous opioids in selfinjurious behavior, is the "pain" or "analgesia" model. This theory postulates that there are high levels of circulating $\beta$-endorphins that override or significantly decrease the experience of pain. The self-injurious behavior is thus considered another form of self-stimulatory behavior, and the pain associated with the self-injurious behavior is masked by means of the endogenous opiate system. Higher levels of $\beta$-endorphins were found in both patients who engaged in self-injurious behavior and those who demonstrated self-stimulatory behavior. According to this theory, naltrexone reduces the elevated pain threshold, so the self-injurious behavior diminishes as the individual begins to experience pain associated with the behavior (7).

From a functional perspective, self-injury is seen as maintained via four possible reinforcement processes. These processes differ according to whether the reinforcement is positive or negative. Self-injury may be maintained by negative reinforcement, if the behavior is followed by an immediate decrease or cessation of aversive thoughts or feelings or decrease or cessation of some social event (eg. tension relief, decrease in feelings of anger, peers stop bullying).

Self-injury may also be maintained by positive reinforcement, if the behavior is followed by the occurrence or increase in desired thoughts or feelings or increase in a desired social event (e.g., self-stimulation, feeling satisfied from having "punished" oneself, attention or support).

History of physical or sexual abuse, parental neglect or abandonment, co morbid conditions such as depression, eating disorders, personality disorders (borderline, antisocial, histrionic), alcoholism and illicit drug use are risk factor associated with self-injurious behavior (8). 


\section{Case Report}

An 18 year old boy was admitted to a mental hospital in Nagpur about 10 years ago by his parents because of poor intellectual development, delayed developmental milestones and inappropriate social behavior. The birth and developmental history was not available.

History by nursing staff revealed that, the patient was reasonably well until 2 years ago when he began pulling the hair on the occipital region of the head. This occurred five to ten times a day and lasted about 15-20 minutes each time. He also scratched the skin especially near pinna of left ear and the occipital region. He would not stop even when the skin was bleeding profusely. These behaviour gradually increased in frequency. A main feature was that the self-injurious behavior occurred while alone and was repetitive in nature. He did not engage in behaviours that harm other such as biting, shoving or pushing.

Examination showed a thin built, underdeveloped child with no noticeable deformity except baldness over occipital region of the head and oozing of blood from the left ear pinna due repeated scratching. There were no motor or sensory abnormalities.

He was conscious, cooperative but not communicative due impaired language development. He displayed self-injurious behavior during the mental status examination and resisted when asked to stop the behavior. His social intelligence quotient was 19.

He was treated with sodium valproate $600 \mathrm{mg}$, lithium 900 $\mathrm{mg}$ and risperidone $8 \mathrm{mg}$ for $8-12$ weeks but did not respond adequately. Because of poor response he was started on oral naltrexone $25 \mathrm{mg}$. Within a week there was reduction in selfinjurious behavior. There was marked improvement after about 15 days with near total remission achieved in 4 weeks. During this period lorazepam $2 \mathrm{mg}$ and risperidone $2 \mathrm{mg}$ was continued along with naltrexone.

\section{Discussion}

Our patient showed self-injurious behavior which was stereotypic, done in isolation and episodic, occurring 4-5 times a day. Different modalities of treatment have been tried for selfinjurious behavior. Serotonergic antidepressants are useful in the treatment of self-injurious behaviors in intellectually disabled person (9). Atypical antipsychotics especially risperidone have been used for treatment of aggression and self-injurious behavior (10). The FDA has approved aripiprazole and risperidone for use in children and adolescents for behavioral impairment associated with intellectual disability. There is also evidence for efficacy of lithium in reduction of self-injurious behavior (11).

Similarly topiramate, gabapentine, divalproex sodium and clonidine have been used in the treatment of self-injurious behavior with different degrees of success (12-15)

Naltrexone is an opioid antagonist which probably acts by suppressing the euphoria associated with self-injurious behavior (16-17). Naltrexone should be used when first line agents such as atypical antipsychotics, divalproate sodium and carbamazepine have failed or are contraindicated. Naltrexone is contraindicated in liver dysfunction. Hepatic enzymes should be monitored at baseline, one month and every 6-12 months thereafter. The most common adverse effects are gastrointestinal disturbance and insomnia.
A recent meta- analysis documented significant reduction in selfinjurious behavior in three double-blind placebo-controlled trials of naltrexone in adults with intellectual disability. However one trial did not reported therapeutic benefit with naltrexone (18).

\section{Declaration of interest \\ None declared}

Praveen Navkhare, Consultant Psychiatrist

Abhishek Mamarde, Consultant Psychiatrist

Anand Lade, Consultant Psychiatrist

Regional Mental Hospital, Nagpur, Maharashtra, India.

Corresponding author: Praveen Navkhare

E mail:navkhare22@gmail.com

\section{References}

1. Pattisom EM, Kahan J. The deliberate self harm syndrome. Am J Psychiatry 1983;140(7):867-72

2. Winchel RM, Stanley M. Self-Injurious Behavior: A Review of the Behavior and Biology of Self-mutilation. Am J Psychiatry 1991; 148:306-17.

3. American Psychiatric Association. (2013). Diagnostic and statistical manual of mental disorders (5th ed.). Arlington, VA: American Psychiatric Publishing.

4. Dolan M, Anderson IM, Deakin JF. Relationship between 5-HT function and impulsivety and aggression in male offenders with personality disorder. Br J Psychiatry 2001; 178:352-9

5. Bryson Y, Sakati N, Nyhan WL et al. Self-mutilative behavior in the Cornelia de Lange syndrome. Am J Ment Defic 1971 Nov; 76(3):319-24.

6. Lloyd KG, Hornykeiwicz O, Davidson L, Shannak K, Farley I, Goldstein M, et al. Biochemical evidence of dysfunction of brain neurotransmitters in the Lesch-Nyhan syndrome. N Engl J Med 1981;305:1106-11

7. Thompson, T., Hackerberg, T., Cerulti, D., Baker, D., Axtell, S. Opioid Antagonist Effects on Self-Injury in Adults with Mental Retardation. Am J Ment Retard 1994; 49: 85-102

8. Van der Kolk BA, Perry JC, Herman JL. Childhood origins of self-destructive behavior. Am J Psychiatry1991; 148:1665-1671

9. Janowsky DS, Shetty M, Barnhill J, Elamir B, Davis JM. Serotonergic antidepressant effects on aggressive, self-injurious and destructive/disruptive behaviours in intellectually disabled adults: a retrospective, open-label, naturalistic trial. Int J Neuropsychopharmacol. 2005 Mar;8(1): 37-48

10. Cohen SA, Ihrig K, Lott RS, Kerrick JM. Risperidone for aggression and self-injurious behavior in adults with mental retardation. J Autism Dev Disord. 1998 Jun;28(3):229-33

11. Luchins DJ, Dojka D. Lithium and propranolol in aggression and self-injurious behavior in the mentally retarded. Psychopharmacol Bull. 1989; 25(3):372-5.

12. Smathers SA, Wilson JG, Nigro MA. Topiramate effectiveness in Prader-Willi syndrome. Pediatr Neurol. 2003 Feb;28(2):130-3.

13. Choudhury Habibur Rasul, Khan Golam Mostafa, Evana Nasrin. Role of antiepileptics in Lesch Nyhan Syndrome. Global Advanced Research Journal of Medicine and Medical Sciences Vol. 1(1) pp. 001-004, February, 2012 (http://garj.org/garjmms/index.htm) 
14. Ruedrich S, Swales TP, Fossaceca C, Toliver J, Rutkowski A. Effect of divalproex sodium on aggression and selfinjurious behaviour in adults with intellectual disability: a retrospective review.J Intellect Disabil Res. 1999 Apr;43 ( Pt 2):105-11.

15. Symons FJ, Thompson A, Realmuto G. Clonidine for self injurious behavior. J Am Acad Child Adolesc Psychiatry. 2004 Nov;43(11):1324-5

16. Symons FJ, Thompson A, Rodriguez MC. Self-injurious behavior and the efficacy of naltrexone treatment: a quantitative synthesis. Ment Retard Dev Disabil Res Rev. 2004;10(3):193-200

17. Casner JA, Weinheimer B, Gualtieri CT. Naltrexone and self-injurious behavior: a retrospective population study. J Clin Psychopharmacol. 1996 Oct;16(5):389-94

18. Rana F, Gormez A, Varghese S. Pharmacological interventions for self-injurious behaviour in adults with intellectual disabilities. Cochrane Database Syst Rev. 2013 Apr 30;4 